\title{
Perbandingan Unjuk Kerja Dan Konsumsi Bahan Bakar Motor Yang Memakai CDI Limiter Dan CDI Unlimiter
}

\author{
Hera Priyatno $^{1, a)}$, J.Victor Tuapetel ${ }^{2, b)}$ \\ 1,2 Program Studi Teknik Mesin ITI, \\ J1. Raya Puspiptek Serpong, Tangerang Selatan-Banten, Indonesia, 15320 \\ a) priyatno.hera@yahoo.co.id, b) jvictor_tuapetel@yahoo.com
}

\begin{abstract}
Abstrak
Sistem pengapian merupakan sistem yang sangat penting pada sepeda motor yang berfungsi untuk mengatur proses pembakaran campuran bahan bakar dan udara. Pengujian dilakukan pada CDI limiter dan CDI unlimiter dengan motor Suzuki Satria F $150 \mathrm{cc}$, pada pengujian ini menggunakan alat dynamometer untuk mengetahui karakteristik daya dan torsi sepeda motor, sedangkan untuk pengujian konsumsi bahan bakar digunakan alat tabung ukur. Pengambilan data dilakukan pada putaran mesin $5000 \mathrm{rpm}, 7000 \mathrm{rpm}$, dan $9000 \mathrm{rpm}$. Hasil pengujian menunjukkan adanya perbedaan daya, torsi dan konsumsi bahan bakar yang dihasilkan oleh kedua CDI. Pada CDI limiter dengan daya ditentukan yakni $(6,05 \mathrm{hp}),(10,13 \mathrm{hp}),(12,39 \mathrm{hp})$, akan menghasilkan torsi sebesar $(8,62 \mathrm{Nm}),(10,30 \mathrm{Nm})$, $(9,80 \mathrm{Nm})$, serta konsumsi bahan bakar $(17,5 \mathrm{ml} / \mathrm{menit}),(24,9 \mathrm{ml} / \mathrm{menit}),(29,3 \mathrm{ml} / \mathrm{menit})$. Sedangkan pada CDI unlimiter dengan daya ditentukan yakni $(6,45 \mathrm{hp}),(10,49 \mathrm{hp}),(12,72 \mathrm{hp})$, akan menghasilkan torsi $(9,2$ $\mathrm{Nm}),(10,67 \mathrm{Nm}),(10,07 \mathrm{Nm})$, serta konsumsi bahan bakar $(14,8 \mathrm{ml} / \mathrm{menit}),(23,1 \mathrm{ml} / \mathrm{menit}),(27,8 \mathrm{ml} / \mathrm{menit})$. Adanya kenaikan daya dan torsi pada CDI unlimiter dan pada konsumsi bahan bakar lebih irit.
\end{abstract}

Kata Kunci: CDI, konsumsi bahan bakar, unjuk kerja

\begin{abstract}
The ignition system is a system that is very important on motorcycle, which the function is to arrange the combustion process at mixture of fuel and air. The examination had done with Suzuki Satria F 150 cc. In this test uses dynamometer equipment in order to know power and torque characteristic of the motorcycle. While to test the consumption fuel uses measuring tube. The data collected at the engine revolution of $5000 \mathrm{rpm}, 7000 \mathrm{rpm}$, and $9000 \mathrm{rpm}$. The test result shows difference at power, torque and fuel consumption which result from both CDI. With the power at CDI limiter set on $(6,05 \mathrm{hp}),(10,13 \mathrm{hp}),(12,39 \mathrm{hp})$. Torsi $(8,62 \mathrm{Nm}),(10,30 \mathrm{Nm}),(9,80 \mathrm{Nm})$, yield torque respectively of $(8,62 \mathrm{Nm}),(10,30 \mathrm{Nm}),(9,80 \mathrm{Nm})$, and fuel consumption respectively of $(17,5 \mathrm{ml} / \mathrm{minute})$, (24,9 $\mathrm{ml}$ minute), (29,3 ml/ minute). Then with power at CDI unlimiter set on $(6,45 \mathrm{hp}),(10,49 \mathrm{hp}),(12,72 \mathrm{hp})$, yield torque respectively of $(9,2 \mathrm{Nm}),(10,67 \mathrm{Nm}),(10,07 \mathrm{Nm})$, and fuel consumption respectively of $(14,8 \mathrm{ml}$ minute), (23,1 ml/ minute), (27,8 ml/ minute). The increase of power and torque on CDI unlimiter yield more efficient fuel consumption.
\end{abstract}

Keywords: CDI, fuel consumption, performance

\section{PENDAHULUAN}

Sistem pengapian merupakan sistem yang sangat penting pada sepeda motor [1]. Sistem pengapian pada motor bensin berfungsi mengatur proses pembakaran campuran bensin dan udara di dalam silinder sesuai waktu yang sudah ditentukan yaitu pada akhir langkah kompresi. Sistem pengapian ini sangat berpengaruh pada daya, torsi dan konsumsi bahan bakar yang dibangkitkan oleh mesin tersebut.

Sistem pengapian khususnya pada motor bensin 4 langkah telah mengalami banyak penyempurnaan. Pada saat awal sepeda motor mulai diproduksi sistem pengapian pada motor bensin menggunakan sistem pengapian konvensional (platina). Sistem pengapian konvensional merupakan sistem pengapian yang menggunakan platina (contact breaker) untuk memutus dan menghubungkan tegangan baterai kekumparan primer. Pada saat ini sistem pengapian konvensional pada sepeda motor telah mengalami perkembangan yaitu sistem pengapian CDI (Capasitor Discharge Ignition). Sistem pengapian konvensional pada saat ini sudah mulai ditinggalkan oleh para produsen motor dan beralih ke sistem pengapian $C D I$, karena di dalam sistem pengapian konvensional masih banyak kelemahan yang ditimbulkan. Salah satunya adalah jumlah pengapian terbatas sekitar 12000 loncatan bunga api per menit, sistem ini perlu disinkronisasikan atau dengan kata lain pada interval waktu yang pendek, kontak pemutus perlu distel kembali.

Sistem pengapian $C D I$ ini menurut sumber arus yang digunakan dibedakan menjadi dua jenis, yaitu $C D I-A C$ dan $C D I-D C$. Sistem $C D I-A C$ adalah sistem pengapian elektronik dengan sumber arus listrik berasal dari koil eksitasi. Pada CDI ini pengapian yang terjadi tidak setabil, karena arus yang digunakan oleh sistem pengapian ini tergantung oleh putaran mesin. Hal tersebut akan membuat pengapian yang terjadi pada putaran 
rendah kurang optimal. Sistem pengapian $C D I-D C$ adalah sistem pengapian elektronik dengan sumber arus listrik berasal dari baterai, sehingga pengapian yang terjadi lebih stabil dari putaran rendah sampai putaran tinggi.

Saat ini kebanyakan sepeda motor diproduksi dengan menggunakan sistem pengapian CDI limiter. CDI limiter adalah $C D I$ yang memiliki batasan dalam memercikan bunga api ke dalam ruang bakar pada rpm tertentu dan percikan bunga api yang dihasilkan pada putaran tinggi relatif kurang stabil. Biasanya $C D I$ pada motor bawaan pabrik ini memiliki limiter sekitar 8000 rpm sampai 9000 rpm. Guna mengatasi kelemahan dari CDI limiter (standar) ini dan untuk memperoleh performa mesin yang lebih optimal, maka banyak pabrikan CDI yang menawarkan CDI unlimiter (BRT Powermax Dualband) sebagai pengganti CDI limiter. CDI unlimiter adalah CDI yang kerjanya tanpa ada batasan pengapian dan mampu melayani kerja mesin pada rpm tinggi tergantung dari seberapa kuat mesin sepeda motor tersebut berputar. Sebenarnya CDI unlimiter juga memiliki batasan dalam memercikan api hingga $20.000 \mathrm{rpm}$.

Penelitian pada tugas akhir ini membandingkan $C D I$ Limiter (Standar) dan CDI Unlimiter (BRT Powermax Dualband) untuk mengetahui perbedaan daya, torsi dan konsumsi bahan bakar.

Penulis membatasi masalah pada perbedaan daya dan torsi pada sepeda motor yang mempergunakan $C D I$ limiter dan CDI unlimiter. Seberapa besar perbedaan konsumsi bahan bakar pada sepeda motor yang mempergunakan CDI limiter dan CDI unlimiter.

Tujuan penelitian yang dicapai adalah untuk mengetahui perbedaan unjuk kerja pada sepeda motor yang mempergunakan CDI limiter dan CDI unlimiter. Untuk mengetahui perbedaan konsumsi bahan bakar pada sepeda motor yang mempergunakan $C D I$ limiter dan $C D I$ unlimiter.

\section{Teori Dasar}

Saat pengapian campuran bahan bakar adalah saat terjadinya percikan bunga api pada busi beberapa derajat sebelum titik mati atas (TMA) pada akhir langkah kompresi. Untuk memperoleh daya yang maksimum dari suatu operasi hendaknya penyalaan diatur sedemikian rupa sehingga tekanan gas maksimum terjadi pada saat torak berada di sekitar 15 sampai 20 derajat engkol sebelum TMA. Jadi, penyalaan yang baik bergantung pada kecepatan perambatan nyala, jarak perambatan nyala maksimum, dan kecepatan poros engkol [2]. Bila pengapian terjadi terlalu awal (sudut pengapian terlalu besar), maka gas sisa yang belum terbakar, pada pembakaran sempurna setelah penyalaan dimulai, api menjalar dari busi dan ke seluruh arah dalam waktu yang sebanding, dengan 20 derajat sudut engkol atau lebih untuk membakar campuran sampai mencapai tekanan maksimum.

Bila pengapian terjadi terlalu lambat, beberapa pukulan berkurang, maka terjadi penurunan daya [3]. Tetapi dapat dibayangkan bahwa pengapian lambat dapat mengakibatkan terbakar sendiri. Bila pengapian terlambat, jadi ruang di atas piston pada akhir pembakaran sudah membesar bahwa sebagian kecil dari kalor berubah menjadi tekanan. Akibatnya adalah sisa kalor dalam jumlah besar tertinggal di dalam motor.

Waktu pengapian yang dimajukan (timming advance) yaitu sudut pengapian maju beberapa derajat sebelum TMA ketika percikan busi menyalakan campuran bahan bakar di dalam ruang bakar selama langkah kompresi [4]. Waktu pengapian yang mundur (retaded timming) dapat didefinisikan sebagai merubah sudut pengapian sehingga campuran bahan bakar dan udara terjadi lebih lambat dari waktu yang ditentukan oleh pabrik.

\section{A. Sistem Pengapian CDI-AC}

Sistem pengapian CDI jenis arus bolak-balik atau yang biasa disebut dengan CDI AC (Alternating Current) merupakan suatu jenis CDI yang sumber arusnya berasal dari source coil (koil pengisi) yang terdapat di dalam flywheel magnet. Diagram sistem pengapian CDI AC ditunjukkan pada gambar 1.

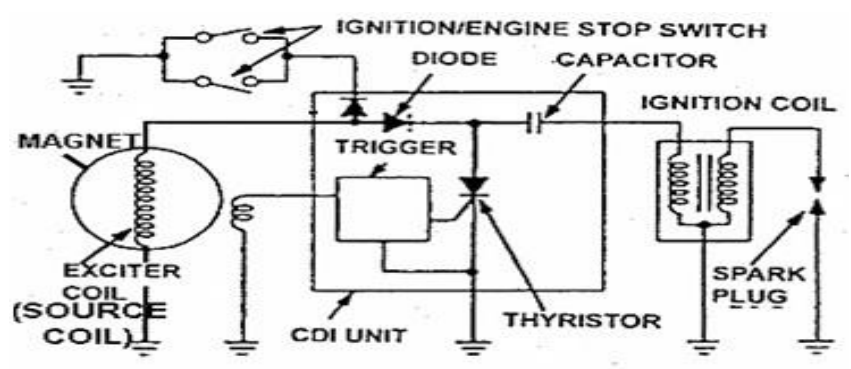

Gambar 1. Diagram rangkaian $C D I-A C$.

\section{B. Sistem Pengapian CDI-DC}

Sistem pengapian CDI-DC menggunakan arus yang bersumber dari baterai, berbeda dengan CDI-AC yang bersumber dari source coil (koil pengisi/sumber). Prinsip dasar CDI-DC (Direct Current) dapat dilihat pada gambar 2.

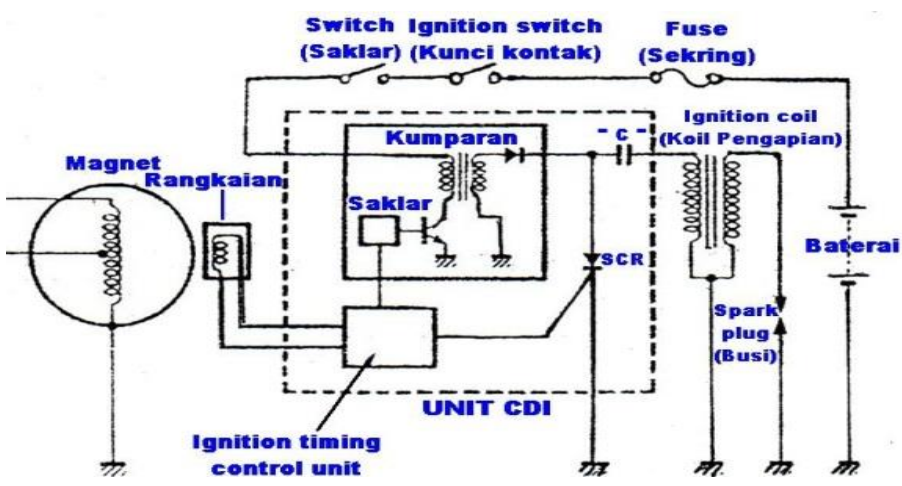

Gambar 2. Diagram sistem pengapian $C D I-D C$

\section{Metodologi}

\section{A. Jenis Penelitian}

Dalam penelitian ini, perlakuan berupa perbedaan jenis CDI yang digunakan pada sepeda motor. Kemudian akan dilihat hasilnya berupa perubahan yang terjadi pada daya, torsi dan konsumsi bahan bakar pada masing-masing variasi putaran $5000 \mathrm{rpm}, 7000 \mathrm{rpm}$ dan $9000 \mathrm{rpm}$.

\section{B. Teknik Analisis Data}

Teknik analisis data yang dipakai dalam penelitian menggunakan teknik analisis deskriptif yaitu mengamati 
dan mencatat secara langsung hasil eksperimen kemudian menyajikannya dalam bentuk tabel dan polygon sesuai hasil dari penelitian yang telah dilakukan. Data yang dihasilkan yaitu daya (hp), torsi (Nm) dan konsumsi bahan bakar (ml/menit). Penggambaran dari fenomena yang terjadi selama penelitian ditunjukan dalam tabel dan polygon yang menggambarkan perbedaan antara CDI limiter dengan CDI unlimiter terhadap daya, torsi dan konsumsi bahan bakar pada sepeda motor Suzuki Satria F $150 \mathrm{cc}$.

\section{Variabel Penelitian}

Variabel adalah suatu yang berbeda atau bervariasi, penekanan kata sesuatu diperjelas dalam definisi kedua yaitu simbol atau konsep yang diasumsikan sebagai perangkat nilai-nilai [1]. Variabel dalam penelitian ini adalah:

- Daya (besarnya kerja motor selama kurun waktu tertentu dalam satuan hp).

- Torsi (kekuatan berputar dalam satuan Nm).

- Konsumsi bahan bakar (banyaknya bahan bakar yang dikonsumsi dalam satuan $\mathrm{ml} / \mathrm{menit}$ ).

Variabel kontrol yaitu semua faktor yang dapat mempengaruhi hasil kerja yang dilakukan oleh mesin yang dikendalikan sama meliputi suhu kerja mesin kurang lebih $80^{\circ} \mathrm{C}$ dan suhu ruangan kurang lebih $30^{\circ} \mathrm{C}$.

\section{Hasil penelitian}

Analisis perbandingan daya rata-rata yang dihasilkan pada motor yang mempergunakan CDI standar (limiter) dan CDI BRT Powermax Dualband (unlimiter) untuk lebih jelasnya ditunjukkan pada tabel 1 dan gambar 3 .

Gambar 3 memperlihatkan daya yang dihasilkan pada CDI unlimiter memiliki nilai rata-rata yang lebih tinggi jika dibandingkan dengan CDI limiter. Perbedaan daya yang dihasilkan oleh kedua jenis CDI ini dikarenakan perbedaan besar pengapian yang dihasilkan CDI tersebut. Daya yang dihasilkan pada motor sangat dipengaruhi oleh besarnya bunga api yang dihasilkan oleh busi, karena semakin besar pengapian yang dihasilkan maka pembakaran yang dihasilkan pada silinder menjadi lebih baik.

Tabel 1. Perbandingan daya rata-rata motor yang mempergunakan CDI limiter dan CDI unlimiter

\begin{tabular}{|c|c|c|}
\hline \multirow{2}{*}{ RPM } & \multicolumn{2}{|c|}{ Daya (hp) } \\
\cline { 2 - 3 } & CDI Limiter & CDI Unlimiter \\
\hline 5000 & 6.06 & 6.45 \\
\hline 7000 & 10.13 & 10.49 \\
\hline 9000 & 12.39 & 12.72 \\
\hline
\end{tabular}

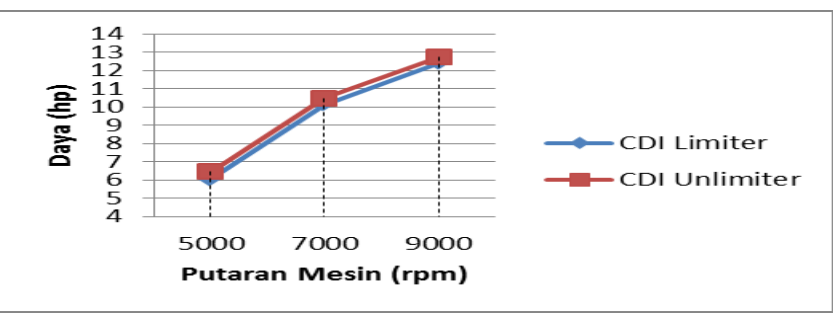

Gambar 3. Grafik daya rata-rata motor terhadap putaran mesin
Analisis perbandingan torsi (Nm) yang dihasilkan pada motor yang mempergunakan CDI standar (limiter) dan CDI BRT Powermax Dualband (unlimiter) untuk lebih jelasnya dapat dilihat pada tabel 2 dan gambar 4 .

Gambar 4 memperlihatkan torsi yang dihasilkan pada CDI unlimiter memiliki nilai rata-rata yang lebih tinggi jika dibandingkan dengan CDI limiter. Besarnya pengapian yang dihasilkan oleh CDI sangat mempengaruhi besar kecilnya torsi yang dihasilkan pada sepeda motor yang menggunakan CDI limiter dengan CDI unlimiter, karena hal ini berhubungan dengan gaya tekan pembakaran yang dihasilkan pada silinder piston.Gaya tekan pembakaran akan maksimal manakala percikan bunga api yang dihasilkan oleh busi lebih besar, sehingga campuran bahan bakar yang telah disemprotkan ke dalam ruang bakar akan terbakar sempurna dan gaya tekan pembakaran akan maksimal.

Tabel 2. Perbandingan torsi rata-rata motor yang mempergunakan CDI limiter dan CDI unlimiter

\begin{tabular}{|c|c|c|}
\hline \multirow{2}{*}{ RPM } & \multicolumn{2}{|c|}{ Torsi (Nm) } \\
\cline { 2 - 3 } & CDI Limiter & CDI Unlimiter \\
\hline 5000 & 8.62 & 9.2 \\
\hline 7000 & 10.3 & 10.67 \\
\hline 9000 & 9.8 & 10.07 \\
\hline
\end{tabular}

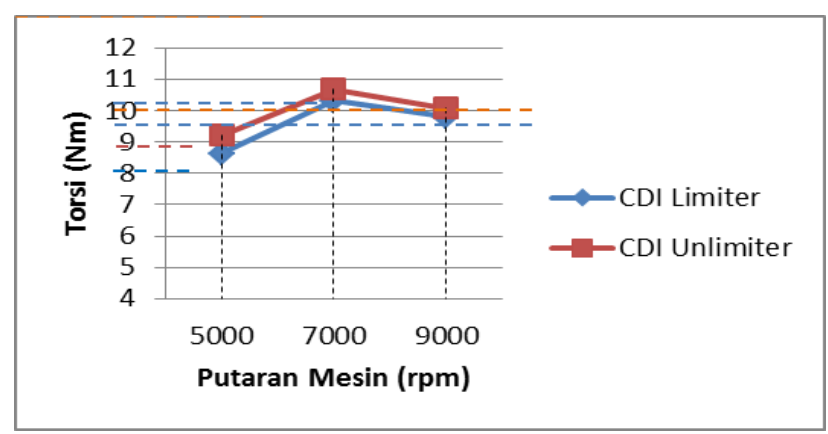

Gambar 4. Grafik torsi rata-rata motor terhadap putaran mesin

Analisis perbandingan laju bahan bakar yang dihasilkan pada motor yang mempergunakan CDI standar (limiter) dan CDI Powermax Dualband (unlimiter) untuk lebih jelasnya dapat dilihat pada tabel 3 dan gambar 5 .

Gambar 5 menujukkan bahwa hasil penelitian, menujukkan konsumsi bahan bakar yang dihasilkan pada CDI unlimiter memiliki nilai rata-rata yang lebih rendah jika dibandingkan dengan CDI limiter. Besarnya pengapian yang dihasilkan oleh CDI sangat mempengaruhi konsumsi bahan bakar, karena dengan pengapian yang lebih baik (besar) campuran bahan bakar yang terdapat diruang bakar akan terbakar dengan sempurna, sehingga tenaga yang dihasilkan akan lebih besar, karena lebih besar maka konsumsi bahan bakar akan lebih irit. Apabila pengapian yang kecil (buruk) maka campuran bahan bakar yang terdapat diruang bakar akan terbakar tidak sempurna, sehingga tenaga yang dihasilkan tidak maksimal, sehingga konsumsi bahan bakar akan lebih banyak (boros).

Dari penelitian yang telah dilakukan pada sepeda motor Suzuki Satria F 150 cc dapat disimpulkan laju 
konsumsi bahan bakar yang dihasilkan oleh motor yang mempergunakan CDI unlimiter lebih rendah (irit) dari pada motor yang mempergunakan CDI limiter

Tabel 3. Perbandingan laju konsumsi bahan bakar rata-rata motor yang mempergunakan CDI limiter dan CDI unlimiter

\begin{tabular}{|c|c|c|}
\hline \multirow{2}{*}{ RPM } & \multicolumn{2}{|c|}{ Laju Bb (ml/mnt) } \\
\cline { 2 - 3 } & CDI Limiter & CDI Unlimiter \\
\hline 5000 & 17.5 & 14.8 \\
\hline 7000 & 24.9 & 23.1 \\
\hline 9000 & 29.3 & 27.7 \\
\hline
\end{tabular}

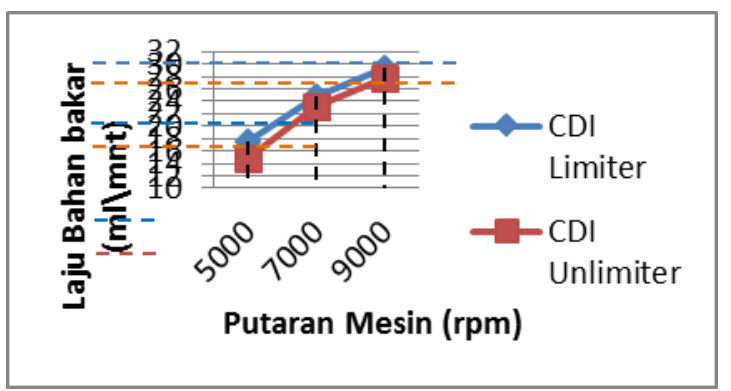

Gambar 5. Grafik laju konsumsi bahan bakar rata-rata motor terhadap putaran mesin

\section{Kesimpulan}

Berdasarkan analisis data dan pembahasan yang telah dilakukan, terdapat perbedaan daya, torsi, dan konsumsi bahan bakar pada motor Suzuki Satria F 150 cc dengan variasi CDI standar (limiter) dengan CDI (unlimiter) pada masing-masing putaran dapat disimpulkan bahwa:

1. Pengaruh pengantian CDI terhadap daya yang dihasilkan terjadi kenaikan. Pada putaran 5000 rpm motor yang mempergunakan CDI limiter daya yang dihasilkan sebesar 6,05 hp sedangkan pada CDI unlimiter sebesar 6,45 hp sehingga terjadi kenaikan sebesar 0,40 hp. Pada putaran $7000 \mathrm{rpm}$ motor yang mempergunakan CDI limiter daya yang dihasilkan sebesar 10,13 hp sedangkan pada CDI unlimiter sebesar 10,49 hp sehingga terjadi kenaikan sebesar 0,36 hp. Dan pada putaran 9000 rpm pada motor yang mempergunakan CDI limiter daya yang dihasilkan sebesar 12,39 hp sedangkan pada CDI unlimiter sebesar $12,72 \mathrm{hp}$ sehingga terjadi kenaikan sebesar $0,33 \mathrm{hp}$.

2. Pengaruh pengantian CDI terhadap torsi yang dihasilkan terjadi kenaikan. Pada putaran 5000 rpm motor yang mempergunakan CDI limiter torsi yang dihasilkan sebesar 8,62 Nm, sedangkan pada CDI unlimiter sebesar 9,2 $\mathrm{Nm}$ sehingga terjadi kenaikan sebesar 0,58 Nm. Pada putaran $7000 \mathrm{rpm}$ motor yang mempergunakan CDI limiter torsi yang dihasilkan sebesar 10,30 Nm, sedangkan pada CDI unlimiter sebesar 10,67 Nm sehingga terjadi kenaikan sebesar 0,37 Nm. Dan pada putaran $9000 \mathrm{rpm}$ pada motor yang mempergunakan CDI limiter daya yang dihasilkan sebesar $9.80 \mathrm{Nm}$, sedangkan pada CDI unlimiter sebesar 10,07 Nm, sehingga terjadi kenaikan sebesar $0,27 \mathrm{Nm}$.
3. Pengaruh pengantian CDI terhadap konsumsi bahan bakar yang dihasilkan terjadi penurunan. Pada putaran $5000 \mathrm{rpm}$ motor yang mempergunakan CDI limiter konsumsi bahan bakar yang dihasilkan sebesar 17,5 $\mathrm{ml} / \mathrm{mnt}$ sedangkan pada CDI unlimiter sebesar 14,8 $\mathrm{ml} / \mathrm{mnt}$ sehingga terjadi penurunan sebesar 2,7 $\mathrm{ml} / \mathrm{mnt}$. Pada putaran $7000 \mathrm{rpm}$ motor yang mempergunakan CDI limiter konsumsi bahan bakar yang dihasilkan sebesar 24,9 $\mathrm{ml} / \mathrm{mnt}$, sedangkan pada CDI unlimiter sebesar 23,1 $\mathrm{ml} / \mathrm{mnt}$, sehingga terjadi penurunan sebesar 1,8 $\mathrm{ml} / \mathrm{mnt}$. Dan pada putaran $9000 \mathrm{rpm}$ pada motor yang mempergunakan CDI limiter konsumsi bahan bakar yang digunakan sebesar $29,3 \mathrm{ml} / \mathrm{mnt}$ sedangkan pada CDI unlimiter sebesar 27,8 $\mathrm{ml} / \mathrm{mnt}$ sehingga terjadi penurunan sebesar 1,5 $\mathrm{ml} / \mathrm{mnt}$.

4. Semakin baik percikan bunga api yang dihasilkan busi maka daya dan torsi yang dihasilkan motor akan meningkat. Untuk konsumsi bahan bakar justru terjadi sebaliknya, yaitu semakin baik pengapian yang dihasilkan oleh busi maka bahan bakar yang diperlukan akan lebih sedikit.

\section{REFERENSI}

[1] Jama, Jalius dan Wagino, Teknik Sepeda Motor Jilid 1, Direktorat Pembinaan Sekolah Menengah Kejuruan Pendidikan Nasional, 2008.

[2] Arismunandar, Wiranto, Penggerak Mula Motor Bakar Torak, ITB, 2005.

[3] Petrovsky. H, Marine Internal Combustion Engines, Moscow, 1968.

[4] Sarwono. Jonathan, Metode Penelitian Kuantitatif dan Kualitatif, Yogyakarta, 2006. 